\title{
UFN DIGITAL E O ENSINO REMOTO EM 2020: PLANEJAMENTO ADMINISTRATIVO-PEDAGÓGICO E DESENVOLVIMENTO DAS ATIVIDADES ACADÊMICAS
}

\author{
UFN DIGITAL AND REMOTE TEACHING IN 2020: \\ THE ADMINISTRATIVE-PEDAGOGICAL PLANNING AND \\ THE DEVELOPMENT OF ACADEMIC ACTIVITIES
}

\section{Fabiana da Costa Pereira1, Taize de Andrade Machado Lopes², Valeria Iensen Bortoluzzi Fabricio Tonetto Londero ${ }^{4}$ e Iuri Lammel Marques ${ }^{5}$}

\section{RESUMO}

O ano de 2020 será um marco histórico na UFN Digital. O setor responsável pela produção de materiais didáticos para os cursos a distância da Universidade Franciscana (UFN) realizou orientações gerais aos professores acerca da substituição das aulas presenciais por aulas remotas, além de promover capacitações sobre uso do ambiente virtual de aprendizagem Moodle e produção de materiais para as aulas online. Após dois semestres de experiência, buscou-se responder à questão: como este processo foi conduzido pelas equipes responsáveis pelo setor de educação digital da Instituição? O objetivo deste relato é descrever como ocorreu o planejamento administrativo-pedagógico para as aulas remotas no ano de 2020, sob o ponto de vista da UFN Digital, e os principais resultados obtidos com a capacitação de professores realizada pelo setor, para uso do AVA e realização de aulas ao vivo. O relato foi redigido a partir da fala dos participantes da equipe da UFN Digital e da consulta a documentos e dados registrados pela equipe no decorrer do ano. Nas considerações finais, listamos sete insights sobre a relação dos alunos e professores com a tecnologia e, além disso, concluímos que esta experiência deverá acelerar a tendência de educação híbrida.

Palavras-chave: Aulas remotas. Educação Superior. Covid-19.

\section{ABSTRACT}

The year of 2020 will be a historic milestone at UFN Digital. The department responsible to produce teaching materials for online courses at the Franciscan University (UFN) provided general guidance to teachers about the substitution of face-to-face classes to remote classes, in addition to promoting training on the use of the Moodle virtual learning environment and about the production of materials for online classes. After a year of experience with remote teaching in quarantine, we aimed to answer the question: how did the teams responsible for the institution's digital education sector conduct this process? The purpose of this report is to describe how the administrative-pedagogical planning for remote classes took place in 2020, from the point of view of UFN Digital, and the main results obtained with the training of teachers carried out by the department, to use the $V L E$ and conduct live classes. The paper was written based on the description reported by the members of the UFN Digital sector and also based on documents and data recorded by the team throughout the year. In the

${ }^{2}$ Professora do Curso de Jornalismo na Universidade Franciscana - UFN. E-mail: fabiana.costa@ufn.edu.br

${ }^{3}$ Coordenadora de Educação a Distância (desde 05/2018) e do curso de Ciências Econômicas (07/2018) na Universidade Franciscana - UFN. E-mail: taize@ufn.edu.br

${ }^{4}$ Professor Adjunto da Universidade Franciscana - UFN. E-mail: valbortoluzzi@ufn.edu.br

${ }^{5}$ Mestre em Ciência da Computação pela Universidade Federal de Santa Maria. E-mail: fabricio.londero@ufn.edu.br

${ }^{6}$ Professor no curso de Jornalismo e coordenador de produção da UFN Digital na Universidade Franciscana - UFN. E-mail: iuri@ufn.edu.br 
results of this paper, we list seven insights on the relationship between students and teachers with technology and, in addition, we conclude that this experience should accelerate the trend of hybrid education.

Keywords: Remote classes. College education. Covid-19.

\section{INTRODUÇÃO}

O ano de 2020 foi marcante para a educação brasileira, tanto a básica como a superior, em razão da pandemia do coronavírus, que causou o fechamento do setor, para as atividades presenciais, em meados do mês de março. Na ocasião, instituições do sistema privado de ensino optaram por manter o ano letivo em funcionamento, com a realização das chamadas aulas remotas, mediadas por tecnologias analógicas e digitais, considerando a realidade de cada região da cidade, do estado ou do país.

$\mathrm{Na}$ Universidade Franciscana (UFN), o primeiro semestre letivo já estava em andamento quando o município de Santa Maria (RS) entrou em lockdown em 17 de março de 2020. Em razão disso, os professores tiveram poucos dias para começarem a se adaptar ao novo sistema, sempre com apoio institucional, que ampliou sua capacidade de TI (tecnologia da informação) e incentivou o uso de todos os recursos digitais (como as redes sociais e plataformas de streaming) para comunicação em tempo real e realização de aulas ao vivo. Ao mesmo tempo, o setor da educação digital da UFN (a UFN Digital) forneceu suporte tecnológico aos professores, auxiliando-os a configurarem o Moodle e a inserirem conteúdos na plataforma, com a utilização de um template (modelo pré-construído) de curso simplificado.

A expectativa, na época, era a de que em maio voltaríamos às aulas presenciais. Como essa expectativa não se concretizou, a instituição passou a organizar o segundo semestre já com um planejamento para educação remota, com a promoção de atividades de capacitação docente realizadas entre julho e agosto deste ano.

Após dois semestres de experiência, buscou-se responder à questão norteadora: como este processo foi conduzido pelas equipes responsáveis pelo setor de educação digital da Instituição? Para isso, foi definido como objetivo deste relato descrever como ocorreu o planejamento administrativo-pedagógico para as aulas remotas no ano de 2020, sob o ponto de vista da UFN Digital, e os principais resultados obtidos com a capacitação de professores realizada pelo setor, para uso do AVA e realização de aulas ao vivo.

Com este relato, queremos destacar o protagonismo da UFN Digital na formação docente para o uso de tecnologias digitais em cursos presenciais ou híbridos. Para tanto, apresentamos um pequeno histórico da UFN Digital, seguido de uma breve descrição da sua estrutura e funcionamento, dando destaque para a atuação junto aos professores nos encaminhamentos para o ensino remoto. $\mathrm{O}$ artigo 
foi produzido a partir dos relatos de experiência dos participantes da equipe da UFN Digital e, também, a partir da consulta a documentos e dados registrados pela equipe no decorrer do ano.

\section{O ENSINO DIGITAL NA UNIVERSIDADE FRANCISCANA}

A Universidade Franciscana se credenciou para a oferta de cursos superiores na modalidade de Educação a Distância em 2018. Entretanto, desde o início dos anos 2000, a instituição mantém uma equipe para a produção de objetos de aprendizagem. Essa história começa com a participação da UFN no projeto RIVED, do Ministério da Educação. Após o encerramento do projeto, foi criado o Mais Unifra, repositório de materiais didáticos multimídia, aberto ao público em geral (LOPES, 2018).

Com a autorização dada pelo Ministério da Educação para a oferta de cursos superiores EAD na UFN, a universidade passou a ofertar cursos de graduação e pós-graduação lato sensu a distância. Ao longo dos anos, a organização do setor passou por aprimoramentos, a partir de estudos dos processos internos e experiência com a modalidade por parte da equipe.

A UFN Digital é um órgão de apoio vinculado ao Gabinete da Reitora, mas os serviços prestados são transversais a toda Instituição, já que a oferta de cursos a distância envolve todos os níveis acadêmicos (extensão, graduação e pós-graduação lato sensu). Atualmente, o organograma do setor é ilustrado na Figura 1.

Figura 1 - Organização do setor UFN Digital

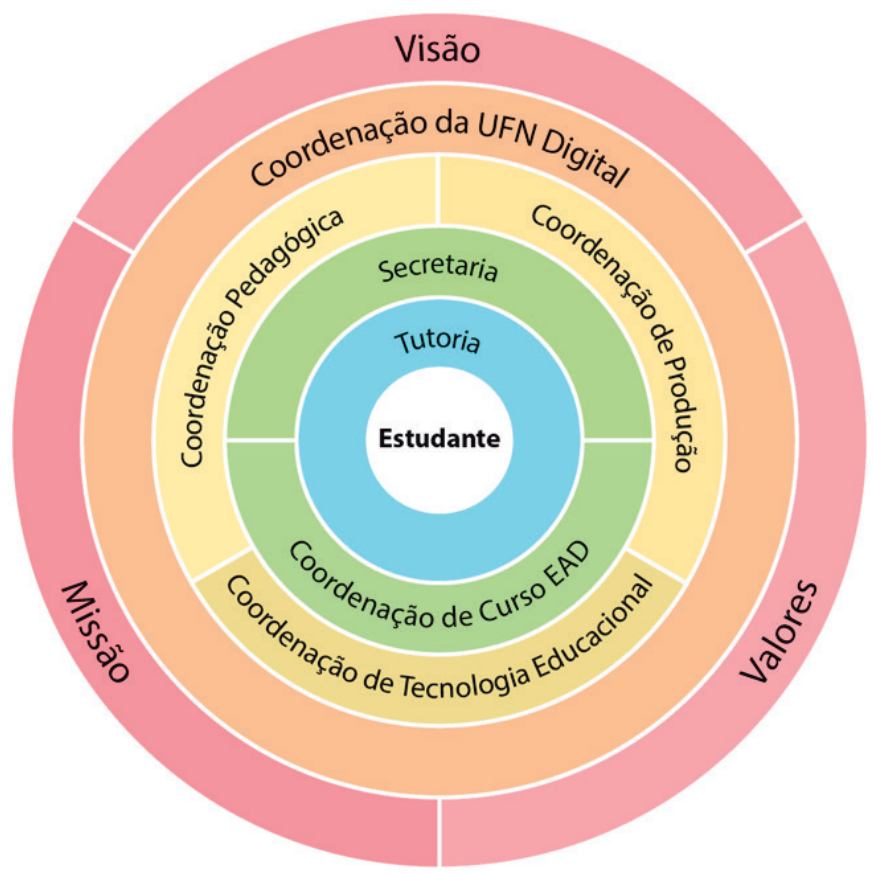

Fonte: UFN Digital 
A produção de conteúdo multimídia na UFN Digital exige uma organização complexa da equipe. No primeiro semestre de 2020 foram produzidas 65 disciplinas/cursos, 33 livros didáticos para cursos de graduação, 1.320 questões de fixação, 495 questões para provas, 225 objetos de aprendizagem, que envolveram 114 professores autores. O Setor Pedagógico é responsável pela orientação da produção dos conteúdos pelos professores autores e o Setor de Produção orienta, realiza e edita as gravações de conteúdos em áudio e vídeo. O Setor de Tecnologia Educacional resolve questões vinculadas ao AVA Moodle, em parceria com a Unidade de Tecnologia da Informação (TI) da Instituição.

Após os conteúdos serem planejados, produzidos, validados e inseridos no ambiente virtual de aprendizagem, os professores mediadores ministram as disciplinas, com o auxílio do tutor do curso. A gestão administrativo-pedagógica dos cursos de extensão, graduação e pós-graduação lato sensu a distância também é realizada por coordenadores de curso, seguindo o mesmo modelo institucional para a modalidade presencial. Todo o processo descrito - do planejamento à oferta - é sistematizado e organizado pelo Controle de Produção da Educação Digital - CPED, um sistema de controle criado pela equipe da UFN Digital, como auxílio às atividades diárias do setor.

No gráfico 1, podemos visualizar o número de matrículas em cursos a distância na UFN, em todos os níveis acadêmicos e no Quadro 1, o catálogo de cursos a distância disponível em dezembro de 2020.

Gráfico 1 - Número de matriculados nos cursos produzidos pela UFN Digital.

600

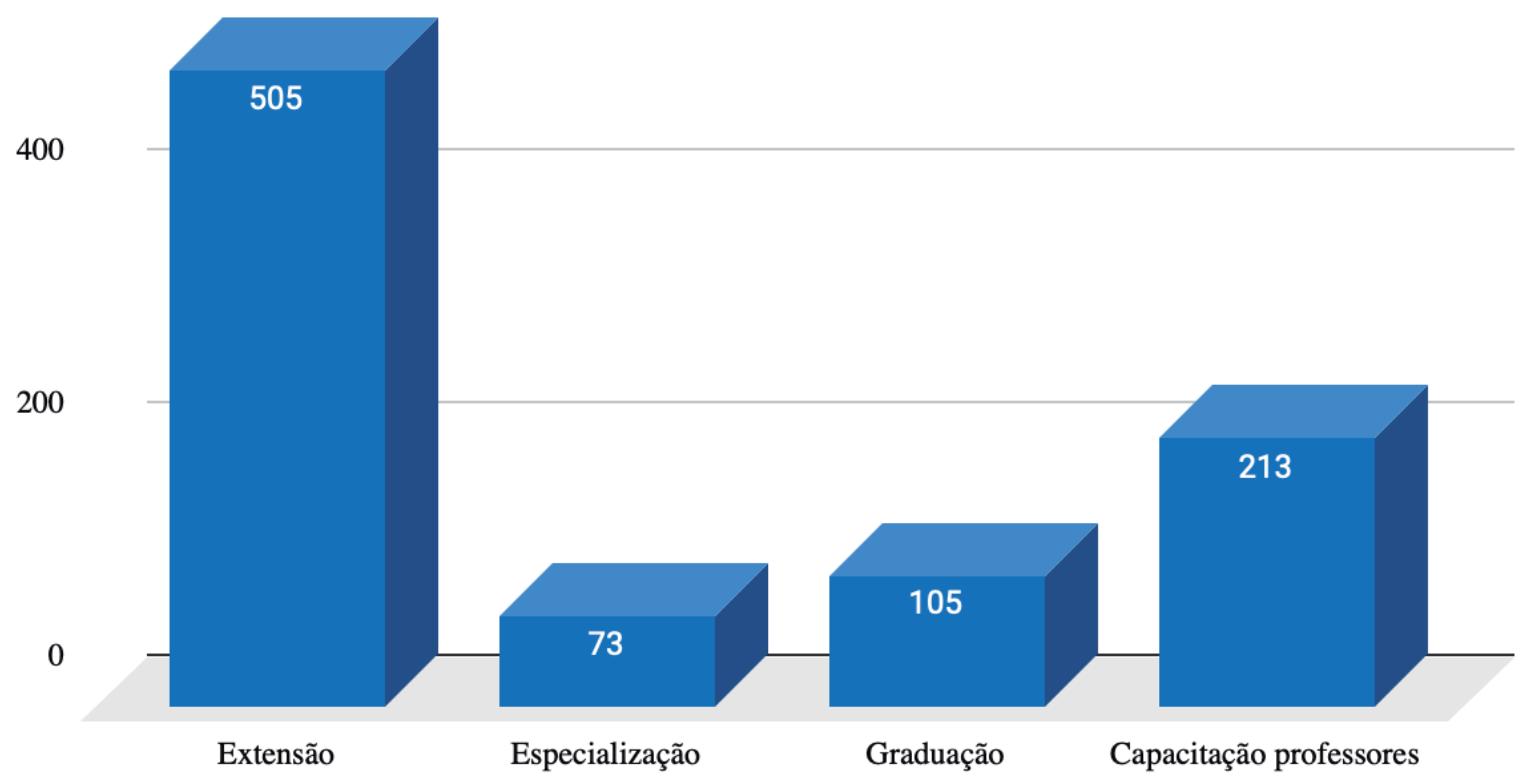

Fonte: Dados acadêmicos UFN - Sistema Agenda e AVA Moodle. Dados coletados em 01/12/2020. 
Quadro 1 - Cursos a distância em oferta (dezembro de 2020) na UFN.

\begin{tabular}{|l|l|}
\hline Nível acadêmico & \\
\hline \multirow{4}{*}{ Graduação } & Tecnólogo em Gestão de Recursos Humanos \\
\cline { 2 - 3 } Especialização & Tecnólogo em Marketing \\
\cline { 2 - 3 } & Tecnólogo em Gestão Financeira \\
\cline { 2 - 3 } & Pedagogia \\
\hline \multirow{4}{*}{ Sensu } & Ensino de Humanidades \\
\cline { 2 - 3 } & Ensino de Bioestatística \\
\hline & Ensino de Nanociências e Nanobiotecnologia \\
\hline \multirow{5}{*}{ Extensão } & Relacionamento Interpessoal no Ambiente Profissional \\
\cline { 2 - 3 } & Direitos Humanos e Multiculturalidade \\
\cline { 2 - 3 } & Metodologias Ativas para o Ensino Híbrido \\
\cline { 2 - 3 } & Gestão de Pessoas e Humanização em Saúde \\
\cline { 2 - 3 } & Produção de Conteúdo Educacional Digital para o Ensino Básico e Superior \\
\cline { 2 - 3 } & Planejamento Físico Funcional de Serviços de Alimentação \\
\cline { 2 - 3 } & Nanociências e Nanotecnologia para Iniciantes \\
\hline & Marketing Digital: por onde começar? \\
\hline & Introdução ao Power BI \\
\hline & Gestão e Liderança \\
\hline & Cidades que Educam \\
\hline & Atualização Clínica e Terapêutica em Diabetes Mellitus \\
\hline
\end{tabular}

Um fator interessante a ser destacado é a cidade de origem dos estudantes matriculados nos cursos de especialização e extensão a distância da UFN. A Figura 2 mostra os estados representados em matrículas nas especializações ofertadas pela UFN, caracterizando a expansão geográfica do ensino promovido na Universidade Franciscana, por meio da modalidade EAD.

Figura 2 - Estados de origem dos matriculados nas especializações lato sensu da UFN

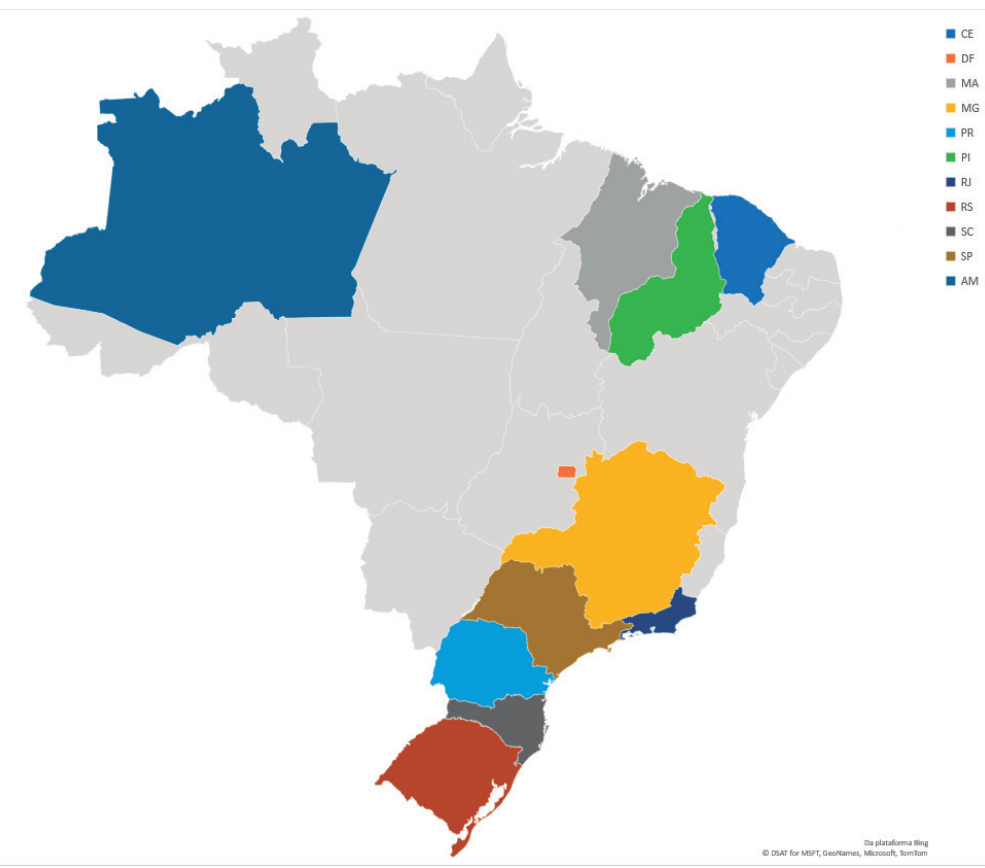

Fonte: Dados acadêmicos. Figura produzida no Microsoft Excel 
Os dados descritos mostram o crescimento da oferta na modalidade a distância na Universidade Franciscana e a abrangência geográfica reitera o reconhecimento nacional da qualidade do ensino.

\section{UFN DIGITAL E O ENSINO REMOTO EM 2020}

O ano de 2020 iniciou com o planejamento institucional pensado e organizado ainda em 2019. Para o setor da UFN Digital, o ano de 2020 representava o ano de expansão dos serviços prestados, caracterizado pela produção de novos cursos de extensão e especialização a distância e a manutenção da produção dos cursos de graduação vigentes.

Entretanto, na segunda quinzena de março de 2020, com o aumento das infecções causadas pelo novo Coronavírus, no Brasil, e especialmente no Rio Grande do Sul, o setor foi desafiado a apresentar um planejamento para a continuidade das aulas presenciais, mas no formato remoto. Nesse contexto, a equipe da UFN Digital analisou as possibilidades de manutenção das aulas em meios digitais, com os recursos tecnológicos disponíveis na Universidade Franciscana. O quadro 2 apresenta a sistematização do planejamento inicial apresentado à Reitoria.

Quadro 2 - Modelo para aulas remotas apresentado pela UFN Digital.

\begin{tabular}{|l|l|}
\hline \multicolumn{1}{|c|}{ Recursos } & \multicolumn{1}{c|}{ Ações da UFN Digital } \\
\hline Ambiente virtual de aprendizagem: Moodle. & $\begin{array}{l}\text { Gravação e disponibilização de tutoriais para configuração e edição de conteú- } \\
\text { dos no Moodle. }\end{array}$ \\
\hline Aulas online assíncronas. & $\begin{array}{l}\text { Orientação para utilização de recursos como o software } \text { OBS Studio, para } \\
\text { gravar videoaulas e disponibilização de link no Moodle. }\end{array}$ \\
\hline $\begin{array}{l}\text { Aulas online síncronas: recursos como } \\
\text { Big Blue Button e Microsoft Teams. }\end{array}$ & $\begin{array}{l}\text { Orientação aos professores para manutenção de aulas síncronas no mesmo dia } \\
\text { e horário das aulas presenciais, deixando-as gravadas e disponíveis no Moodle. }\end{array}$ \\
\hline $\begin{array}{l}\text { Textos e livros: biblioteca virtual da UFN, } \\
\text { textos produzidos pelos professores ou } \\
\text { textos disponíveis gratuitamente na Internet. }\end{array}$ & $\begin{array}{l}\text { Orientação para acesso à biblioteca virtual e disponibilização de links das } \\
\text { obras no Moodle. }\end{array}$ \\
\hline $\begin{array}{l}\text { Questionários, atividades e provas no } \\
\text { Moodle }\end{array}$ & $\begin{array}{l}\text { Disponibilização de tutoriais para o professor, acerca da configuração de ativi- } \\
\text { dades por meio de recursos do Moodle. }\end{array}$ \\
\hline
\end{tabular}

Fonte: UFN Digital.

O modelo apresentado visava utilizar os recursos tecnológicos disponíveis na UFN porque era necessária uma transição rápida, mas que mantivesse a qualidade das aulas. Como o AVA Moodle já é utilizado nos cursos a distância, tínhamos tutoriais gravados e expertise para auxiliar os professores da modalidade presencial. Desta forma, a plataforma utilizada pela UFN para aulas remotas foi o ambiente Moodle, uma vez que a plataforma permite o registro das aulas por parte do professor e é uma forma para registrar frequência e notas do estudante. O Moodle também está integrado ao sistema acadêmico institucional e, consequentemente, todos os estudantes matriculados nos cursos presenciais têm acesso direto ao Moodle.

O plano de emergência para substituição das aulas presenciais por aulas em meios digitais foi aprovado e, em 19 de março de 2020, as aulas remotas iniciaram. Houve orientações gerais aos 
coordenadores e professores pela Reitoria e orientações mais específicas sobre uso de tecnologias digitais educacionais por parte da UFN Digital. Como descrevemos anteriormente, o setor tinha diversos tutoriais para uso do Moodle, mas o catálogo de tutoriais foi ampliado, para atender professores e estudantes que ainda não conheciam ou haviam utilizado a sala de aula virtual. Além dos tutoriais gravados, também foram feitos atendimentos e orientações aos professores via videoconferências, telefone ou e-mail.

Nas orientações enviadas aos professores, foi descrito detalhadamente como o professor poderia preparar sua aula no AVA Moodle. A cartilha com as informações foi enviada a todo corpo docente da Universidade Franciscana em 19 de março de 2020, data de início das aulas remotas. O ineditismo da situação nos fez utilizar os conhecimentos adquiridos ao longo dos anos com a modalidade presencial e a distância e traçar um norte para as aulas remotas na UFN, no que se refere ao uso das tecnologias educacionais digitais. Em síntese, as orientações enviadas foram:

\section{a) "Como posso fazer minha aula no ambiente virtual de aprendizagem Moodle? Quais recursos} utilizar?" Foi explicado aos professores que eles poderiam utilizar artigos científicos disponíveis na internet, livros ou capítulos de livros da biblioteca virtual, vídeos do Youtube, áudios elaborados pelo professor ou links para podcasts, slides elaborados no PowerPoint, com inserção de áudio, tarefas com questões dissertativas, questionários com questões objetivas, fórum de debates e videoconferência com os estudantes (aulas ao vivo).

b) “Onde estão disponíveis os tutoriais para aprender a configurar os recursos indicados?" Nesse item, foram inseridos links de 12 tutoriais básicos, desde como acessar o Moodle até como fazer captura de tela com OBS Studio ou gravar uma videoaula utilizando o PowerPoint.

c) “Como acesso os tutoriais no Moodle?" Os tutoriais também foram inseridos no AVA Moodle e, ao longo do semestre, foram sendo expandidos, conforme a demanda dos professores por novos recursos tecnológicos para as aulas remotas. Atualmente, todos os tutoriais estão disponíveis no ambiente virtual de aprendizagem e no sistema acadêmico (conhecido na Instituição como "Agenda"). Para os estudantes, os tutoriais estão disponíveis no sítio da UFN, no link “Covid-19”.

d) "Preciso de ajuda! Quais os canais de atendimento da UFN Digital?" Nesse item, foi inserido um quadro com os nomes da equipe, seus e-mails institucionais, telefones e horários de atendimento, bem como os temas em que cada profissional (professor ou técnico-administrativo) poderia auxiliar. Portanto, caso o professor tivesse ficado com dúvidas após a visualização dos tutoriais, ainda poderia pedir ajuda extra para a equipe. 
e) "Nunca trabalhei com o AVA Moodle. Como começar?" Nesse ponto, foi explicado aos professores que eles poderiam começar marcando uma conversa com a equipe da UFN Digital, que iria explicar o passo a passo necessário para abertura e inserção de conteúdos no Moodle.

É importante ressaltar que na UFN há diversos recursos que podem ser utilizados para a realização de videoconferências. Além do Big Blue Button (BBB), há possibilidade de usar o Microsoft Teams (e o Microsoft Stream como repositório das gravações) e mais recentemente, o Google Meet. Os professores têm acesso a essas ferramentas por meio de sua conta de e-mail institucional.

Um ponto que destacamos para a comunidade acadêmica no primeiro semestre de 2020 referia-se às diferenças entre aulas remotas e aulas na modalidade a distância, com base nas portarias publicadas pelo Ministério da Educação acerca do ensino remoto. A partir da experiência da equipe, e de referências bibliográficas disponíveis no período da interrupção das aulas presenciais, a UFN Digital produziu o card ilustrado na Figura 3.

Figura 3 - Diferenças entre aulas remotas e aulas na modalidade a distância.

\section{CONHEÇA AS DIFERENÇAS DAS MODALIDADES}

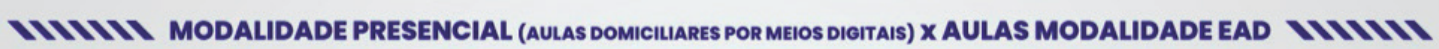
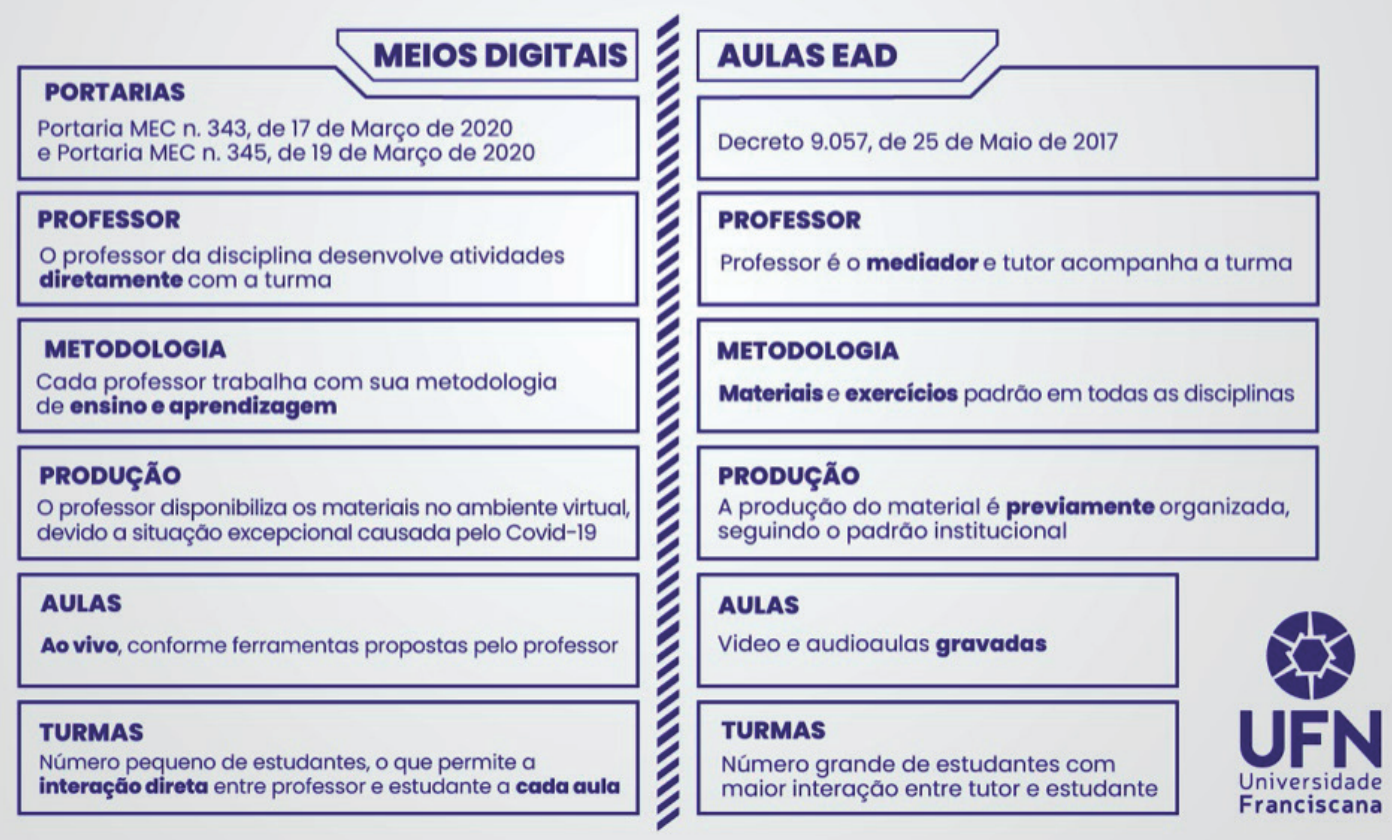

Fonte: UFN Digital. 
O primeiro semestre de 2020 transcorreu apresentando muitos desafios aos setores da UFN, professores e estudantes. No que se refere à UFN Digital, houve continuidade da produção de cursos a distância por parte da equipe, em um primeiro momento no regime de home office (abril de 2020). Concomitantemente, eram produzidos mais tutoriais de uso do Moodle, Microsoft Teams ou de gravação e edição de videoaulas, conforme a demanda dos professores para as aulas remotas.

A partir de pesquisas de satisfação com aulas no primeiro semestre de 2020, realizadas com estudantes dos cursos de Administração, Ciências Contábeis e Ciências Econômicas, além de escuta das necessidades dos professores e coordenadores de curso, foi proposta uma capacitação docente entre julho e agosto, além da disponibilização de tutoriais para os estudantes na página de internet da UFN, principalmente à respeito do uso do Moodle e do Microsoft Teams, além de noções de netiqueta.

Na capacitação promovida pela UFN Digital, houve 213 professores inscritos (aproximadamente $50 \%$ do corpo docente). Foram disponibilizados 43 tutoriais, em sua maioria vídeos de até 2 minutos. O curso transcorreu entre 20 de julho e 23 de agosto de 2020 e, nesse período, a equipe da UFN Digital respondeu aproximadamente 90 mensagens somente nos fóruns de dúvidas. Os conteúdos trabalhados na capacitação estão descritos no quadro 3.

Quadro 3 - Programa do curso de capacitação Moodle básico para professores.

\begin{tabular}{|c|l|}
\hline Tópico & Conteúdo \\
\hline \multirow{2}{*}{ Tópico 1 - Configurações } & - Orientações aos professores da modalidade presencial \\
iniciais do Moodle & - Como acessar o Moodle da UFN? \\
- Como usar o app Moodle? \\
- Como usar o template da UFN Digital? \\
- Template simplificado para aulas remotas - 20 semanas \\
- Template simplificado para aulas remotas - 40 semanas \\
- Como alterar a visibilidade de uma disciplina no Moodle? \\
- Como criar novos rótulos? \\
\hline - Como visualizar a disciplina com perfil do estudante? \\
- Como alterar a imagem do curso no Moodle? \\
\hline de recursos no Moodle & - Como inserir links externos de recursos no Moodle? \\
& - Como adicionar um arquivo no Moodle? \\
& - Como adicionar o recurso página? \\
& - Como criar uma pasta de arquivo no Moodle? \\
- Exemplo de uma sequência didática no Moodle \\
- Exemplo de uma disciplina organizada com template da UFN Digital \\
- Como importar conteúdos ou disciplinas no Moodle? \\
- Como incorporar videoaulas no Moodle? \\
- Gamificação no Moodle \\
- Como configurar o acompanhamento de progresso no Moodle? \\
\hline
\end{tabular}




\begin{tabular}{|c|c|}
\hline $\begin{array}{c}\text { Tópico } 3 \text { - Configurações básicas } \\
\text { de atividades no Moodle }\end{array}$ & $\begin{array}{l}\text { - Como configurar um fórum de discussão? } \\
\text { - Como o estudante interage em um fórum? } \\
\text { - Como configurar uma videoconferência no Moodle? } \\
\text { - Como criar tarefas dissertativas? } \\
\text { - Como corrigir tarefas dissertativas? } \\
\text { - Como configurar questionários? Parte } 1 \\
\text { - Como configurar questionários? Parte } 2 \\
\text { - Como o estudante responde a um questionário? } \\
\text { - Como elaborar um banco de questões no Moodle e usar em provas? } \\
\text { - Como reorganizar um banco de questões? } \\
\text { - Como reaproveitar um banco de questões? } \\
\text { - Como enviar mensagens para os estudantes? } \\
\text { - Como restringir tópicos, recursos ou atividades no Moodle? } \\
\text { - Como usar a sobreposição de prazos no Moodle? } \\
\text { - Como configurar grupos no Moodle? }\end{array}$ \\
\hline Tópico 4 - Microsoft Teams & $\begin{array}{l}\text { - Como acessar o Teams UFN e fazer aulas ao vivo? } \\
\text { - Como baixar o app do Teams? } \\
\text { - Como criar equipes no Teams e fazer convite para uma live? } \\
\text { - Como acessar remoto via Teams? } \\
\text { - Como ativar o Whiteboard do Teams? } \\
\text { - Como usar o Microsoft Stream? } \\
\text { - Como criar grupos em uma equipe do Teams? } \\
\text { - Como obter o link de uma live no Teams? } \\
\text { - Como adicionar o link de uma aula ao vivo no Moodle? } \\
\text { - Como aplicar uma tela de fundo no Teams? } \\
\text { - Como marcar uma reunião ou aula ao vivo no Teams? } \\
\text { - Como disponibilizar arquivos no Teams para estudantes? } \\
\text { - Manual de netiqueta }\end{array}$ \\
\hline
\end{tabular}

Fonte: UFN Digital.

Entre os materiais externos disponibilizados no curso de capacitação, os professores também tinham acesso a links para:

- $\quad \mathrm{O}$ artigo "The difference between emergency remote teaching and online learning", de Charles Hodges, Stephanie Moore, Barb Lockee, Torrey Trust e Aaron Bond (todos professores de universidades norte-americanas). Esse foi um dos primeiros textos científicos a discutir as características do ensino emergencial provocado pela pandemia do novo Coronavírus. Para os professores da UFN, foi destacado que a alternativa proposta pela instituição ia ao encontro do que universidades em todo mundo estavam realizando ao interromper as aulas presenciais.

- Matéria do sítio da UFN que discute as diferenças entre as aulas remotas (ensino emergencial) e as aulas ofertadas na modalidade a distância.

- Links para canais do YouTube que disponibilizam tutoriais do Moodle e Teams. 
- Conteúdos extras com explicações sobre metodologias ativas, utilização do recurso H5P (sítio de produção de recursos multimídia interativos), captura de tela, edição de vídeos, repositórios de imagens gratuitas e recursos para elaboração de infográficos.

O curso pode ser feito dentro do tempo do professor, desde que observando o período de oferta (quatro semanas). Desta forma, o docente poderia olhar os vídeos tutoriais, tirar as dúvidas no fórum de dúvidas de cada tópico, enquanto planejava as aulas do segundo semestre de 2020, que também seriam remotas. No período de oferta da capacitação, a equipe da UFN Digital realizou três lives com os cursistas, para detalhar algumas configurações do Moodle e Teams e tirar dúvidas dos professores. Aproximadamente 100 professores participaram de cada uma das videoconferências, cujos temas são apresentados no quadro 4.

Quadro 4 - Temas das videoconferências da capacitação promovida pela UFN Digital.

\begin{tabular}{|c|l|}
\hline Videoconferência & \multicolumn{1}{c|}{ Tema } \\
\hline $27 / 07 / 2020$ & $\begin{array}{l}\text { Importância de uma sequência didática clara no Moodle e expectativas dos estudantes sobre as } \\
\text { aulas teóricas remotas, no que se refere à organização do Moodle. }\end{array}$ \\
\hline $05 / 08 / 2020$ & O que é importante saber para a elaboração de provas no Moodle? \\
\hline $11 / 08 / 2020$ & O que é importante saber para a realização de aulas ao vivo e gravação de vídeo/audioaulas? \\
\hline
\end{tabular}
Fonte: UFN Digital.

Dessa forma, aliado ao programa Saberes, vinculado à Pró-reitoria Acadêmica (PROAC), a UFN Digital auxiliou docentes e estudantes a aprimorarem a interação com as tecnologias educacionais digitais. Um ponto interessante do curso foi a implementação do recurso de gamificação LevelUp!, que é um plugin para o AVA Moodle. Gamificação consiste em elementos de jogos aplicados em contextos diferentes, conforme apresenta Flora Alves (2015), e tem como objetivo aumentar o engajamento dos envolvidos, seja em sala de aula ou no trabalho. No LevelUp!, podemos distribuir pontos de experiência entre os 'jogadores' conforme os objetivos são concluídos, tais como participar de um fórum, enviar uma tarefa ou um questionário. Os pontos de experiência (previamente configurados pelo professor) ganhos pelo ‘jogador' são somados pelo plugin e então, conforme um valor é atingido, este 'jogador' sobe de nível. Como fator motivador, um ranking pode ser utilizado para listar os 'jogadores' que mais pontuaram, motivando os participantes a completarem mais objetivos (como estudar e fazer tarefas) para assim ‘alcançarem' os colegas, fato este que podemos constatar na análise dos registros de nosso curso.

Quanto aos resultados da capacitação promovida no recesso de inverno, o gráfico 2 ilustra os pontos avaliados pelos cursistas. 
Gráfico 2 - Avaliação do curso de capacitação promovido pela UFN Digital.

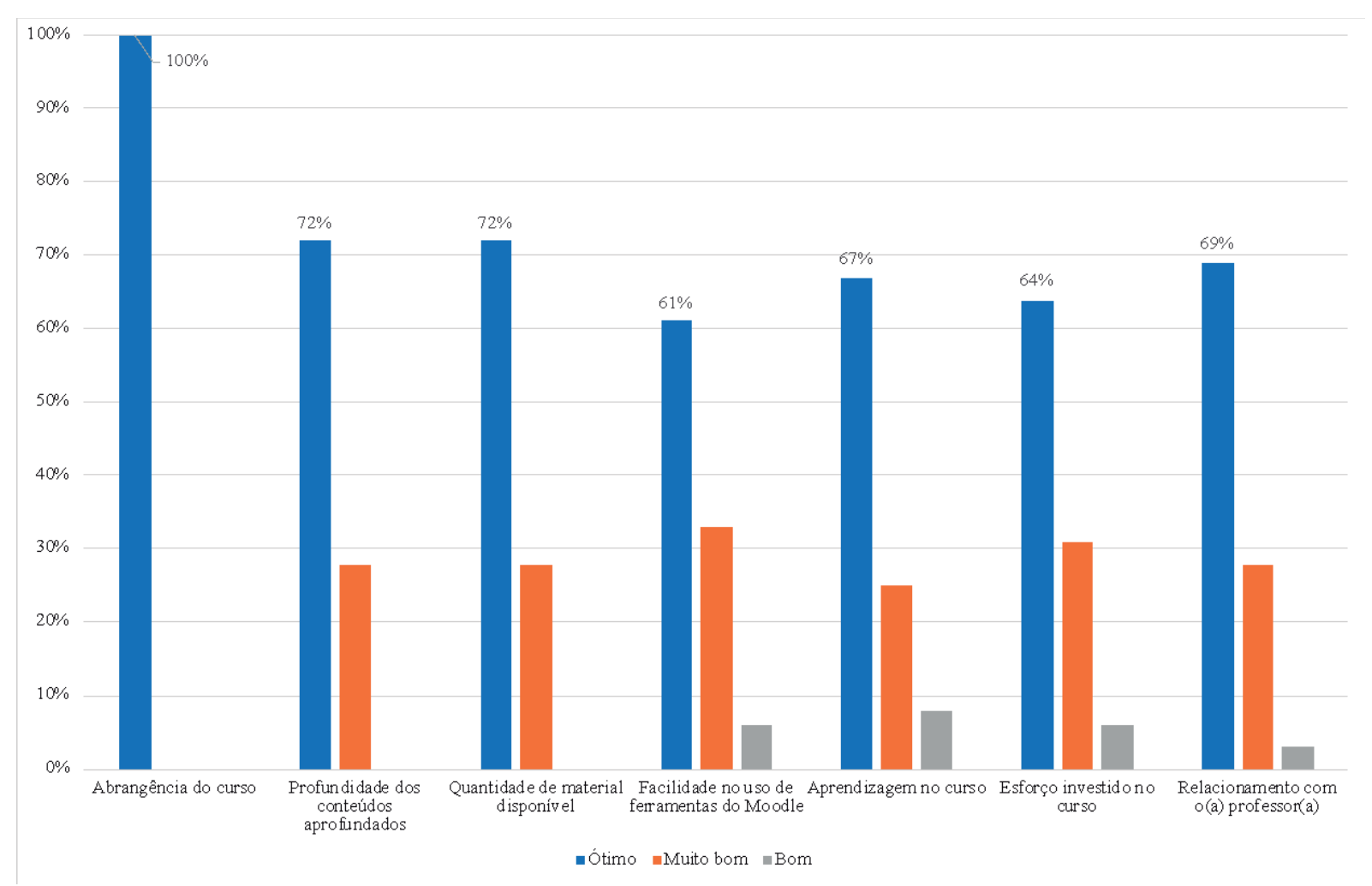

Fonte: UFN Digital.

Consideramos que os resultados do curso foram positivos, pois nos ajudaram a refletir sobre formas de aprimorar novas edições. Juntamente com as questões objetivas aplicadas aos professores, também havia a possibilidade de avaliar o curso de forma descritiva. Recebemos diversos elogios, mas também sugestões de novos conteúdos e aplicações, além de pedidos para deixarmos o curso disponível ao longo do segundo semestre de 2020, de forma que os professores possam voltar aos tutoriais ou fóruns sempre que tiverem dúvidas.

\section{CONSIDERAÇÕES FINAIS: APRENDIZADOS E EXPECTATIVAS}

Ao longo do período de interrupção das aulas presenciais e a substituição por aulas remotas, observamos alguns aspectos interessantes, que compartilharemos nesse relato:

1. os estudantes preferiam ter aulas ao vivo (síncronas), no mínimo, uma vez a cada quinze dias, para manter a interação com professores e colegas. Muitos estudantes inclusive pediam que as aulas ao vivo fossem semanais, para que pudessem manter uma rotina de estudos, apesar da pandemia. Nesse contexto, foi sugerido aos professores que mantivessem as aulas síncronas no mesmo dia e horário das aulas presenciais. Também foi possível 
compreender que os alunos buscavam uma transposição do presencial para o online, o que não caracteriza as aulas remotas como aulas a distância ou híbridas.

2. os estudantes solicitaram que os professores organizassem o AVA Moodle por tópicos, temas ou aulas, para que conseguissem compreender claramente o conteúdo e as tarefas semanais. Para isso, os professores foram orientados a utilizarem o template criado pela UFN Digital. Observamos que os estudantes valorizam quando o professor organiza de forma objetiva a sequência didática. Essa organização por parte do professor, inclusive, minimiza as mensagens de dúvidas que devem ser respondidas.

3. os estudantes também pediram atenção para o volume de conteúdo disponibilizado semanalmente pelos professores. Observamos nas capacitações muitas dúvidas dos professores referentes ao tempo de aula no ensino remoto. Ou seja, nas aulas presenciais, o docente se organiza conforme a hora-relógio, mas isso não é possível, de uma forma direta, nas aulas online. Por isso, a partir da nossa experiência com a modalidade a distância, sugerimos como o professor poderia organizar sua aula no Moodle, bem como compatibilizar a carga horária da disciplina com o planejamento pedagógico semanal. Esse ponto também foi destacado por Appenzeller et al. (2020, s/p), ao descrever a experiência do curso de Medicina da Unicamp com o ensino remoto. Segundo os autores, "em um momento inicial, a maior dificuldade encontrada para a estrutura do curso em modelo remoto foi a inserção de conteúdo excessivo e de forma desorganizada nas plataformas", o que levou a organização de reuniões pedagógicas para debater o tema e orientar os professores.

4. os estudantes pediram que as aulas fossem gravadas e disponibilizadas no Moodle. Esse ponto demonstra duas questões: muitos estudantes tinham dificuldade em assistir as aulas ao vivo, seja porque houve mudança de rotina (pessoal ou profissional) por causa da pandemia, seja por problemas de conexão às aulas ao vivo. Em muitos casos, as conexões próprias dos estudantes demonstraram ser precárias, impedindo-os de ligarem câmera e, até mesmo, o microfone.

5. muitos docentes da modalidade presencial desconheciam a configuração de recursos como AVA Moodle, Microsoft Teams, Google Meet, Zoom etc. Foi preciso uma imersão nos cursos de capacitação promovidos pela UFN, auxílio de outros colegas professores, familiares ou amigos ou a visualização de tutoriais na internet al.ém disso, muito do uso adequado desses recursos se aprende os utilizando, e professores mais curiosos e com vontade de aprender 
novos recursos tecnológicos se destacaram, inclusive, compartilhando seus conhecimentos em outras capacitações institucionais e colaborando para o aprimoramento das aulas remotas da Instituição.

6. entendemos ser importante que, apesar da interrupção das aulas presenciais em março de 2020 e a implementação do ensino remoto emergencial, haja formalização das aulas ministradas pelos professores. Ou seja, na nossa universidade foi fundamental que tenha havido uma escolha institucional por um ambiente virtual de aprendizagem único, em que os professores pudessem organizar a sequência didática da disciplina e que permitisse o registro de frequência e notas dos estudantes. Nesse contexto, o acesso por estudantes e professores ao AVA também foi facilitado e integrado ao sistema acadêmico. Portanto, o ensino remoto é emergencial, mas organizado e bem planejado, dentro do possível.

7. foi fundamental que ouvíssemos coordenadores, professores e estudantes nesse processo. Os professores foram desafiados a reinventar-se em poucas semanas. Alguns já tinham experiência com tecnologias educacionais digitais, mas uma parte muito grande ainda não possuía. Além de orientar os professores no sentido prático, ou seja, a respeito do uso das ferramentas tecnológicas, foi necessário que nós os escutássemos e entendêssemos suas dificuldades, até porque nós também somos professores e, apesar da experiência com a modalidade a distância (o que facilitou nossa transição para o ensino remoto), também estávamos passando pelo mesmo momento. No que se refere aos alunos, também houve muitos desafios, como dificuldades em acessar as aulas, seja por carência de recursos tecnológicos ou falta de prática com o uso do ambiente virtual e ferramentas de videoconferência. Também houve dificuldades pessoais diversas, como desemprego nas famílias, que exigiram resiliência de nossos estudantes e empatia e flexibilidade dos professores. Os coordenadores de curso também foram desafiados e, a partir do acesso completo às disciplinas no Moodle, orientaram professores e estudantes, com objetivo de aprimorar as aulas remotas.

Observa-se que a obrigatoriedade do uso das tecnologias educacionais digitais para a continuidade das aulas em 2020 acelerou uma tendência observada há alguns anos: o ensino híbrido. Professores e estudantes necessitaram se adequar a uma realidade imposta por uma pandemia mundial, mas que, certamente, trará consequências para o futuro da educação, principalmente, no ensino superior. Como afirmam Hodges et al. (2020, s/p), quando o período de pandemia mundial causado pelo novo Coronavírus passar, não podemos simplesmente retornar às práticas anteriores à Covid-19. Há muitas situações que podem trazer impedimentos aos encontros presenciais e os conhecimentos 
apreendidos com o ensino remoto emergencial devem se tornar parte do conjunto de habilidades dos docentes. Também, é importante que as instituições avaliem a implementação do ensino remoto e o quão bem isso foi feito.

Há potencialidades no uso mais intensivo de tecnologias educacionais nas universidades, sobretudo em alinhamento com as metodologias ativas de aprendizagem. Espera-se que os aprendizados obtidos em 2020 (criatividade dos professores ao expor conteúdos com o uso de tecnologias digitais e protagonismo dos estudantes) possam gerar resultados positivos, no sentido de aumentar a qualidade do processo ensino-aprendizagem.

\section{REFERÊNCIAS}

ALVES, Flora. Gamification: como criar experiências de aprendizagem engajadoras. São Paulo: DVS, 2015.

APPENZELLER, Simone; MENEZES, Fábio Husemann; SANTOS, Gislaine Goularte dos; PADILHA, Roberto Ferreira; GRAÇA, Higor Sabino; BRAGANÇA, Joana Fróes. Novos tempos, novos desafios: estratégias para equidade de acesso ao ensino remoto emergencial. Revista Brasileira de Educação Médica. v. 44, out. 2020.

HODGES, Charles; MOORE, Stephanie; LOCKEE, Barb; TRUST, Torrey; BOND, Aaron. The difference between emergency remote teaching and online learning. Educause Review. [S.I.]. 2020. Disponível em: https://bit.ly/35tJnW7. Acesso em: 14 dez. 2020.

LOPES, T. A. M. Produção didática em áudio e vídeo para a EAD: relato de experiência do Laboratório de Educomunicação da Universidade Franciscana, Santa Maria/RS. In: 24 Congresso Internacional ABED de Educação a Distância, 2018, Florianópolis/SC. Anais, 2018. 
